\title{
Carbon Footprint of Royal Jordanian Airlines Ground and Air Operations
}

\author{
Abdul Ghani Albaali (Corresponding author) \\ Visiting Professor, Princess Sumaya University for Technology \\ Amman, Jordan \\ E-mail: ghanialbaali@ hotmail.com; Phone: +962796963116
}

Rita Haddad

Royal Jordanian Airlines, Amman, Jordan

Motasem Saidan, Majid Zeki Hameed

Royal Scientific Society, Amman, Jordan

Received: August 18, 2012 Accepted: October 15, 2012 DOI: 10.5296/jpag.v2i4.2663

\begin{abstract}
Aviation is different from other energy-using activities. Currently it makes about $2 \%$ of the global $\mathrm{CO}_{2}$ emission but it is rising fast. This will negatively affecting on the environment and urges us to pay more attention to the risks of travelling on environment

The principal aviation emissions include the greenhouse gases carbon dioxide $\left(\mathrm{CO}_{2}\right)$, water vapor $\left(\mathrm{H}_{2} \mathrm{O}\right)$, nitrogen oxides (NOx), sulphur oxides ( $\mathrm{SOx}$ ), and soot. The emissions affect the climate through various mechanisms. $\mathrm{CO}_{2}$ has a long atmospheric residence time of about 100 years. It is well mixed throughout the atmosphere and affects the global climate as a green house gas. Aircraft engines represent an increasing and potent source of greenhouse gas emissions, due in part to the unprecedented growth in air travel.

This study highlights for the first time the importance and carbon footprint of Royal Jordanian Airlines aircraft fuel in producing $\mathrm{CO}_{2}$ airborne emissions as well as emissions generated during the flight due to the use of wide variety of products and equipment.
\end{abstract}

Keywords: $\mathrm{CO}_{2}$ emission, LCA software calculations, Royal Jordanian Airlines 


\section{Introduction}

It has become increasingly important to monitor and record carbon dioxide emissions to the atmosphere because climate change has risen up the agenda. Governments, institutions, businesses and individuals have all become engaged in monitoring the size of their carbon footprints, as the first crucial stage towards developing strategies to reduce emissions.

\subsection{Greenhouse Gases GHG}

Greenhouse gases are gases in an atmosphere that absorb and emit radiation within the thermal infrared range. This process is the fundamental cause of the greenhouse effect. The main greenhouse gases in the Earth's atmosphere are water vapor, $\mathrm{CO}_{2}$, methane, nitrous oxide, and ozone. In our solar system, the atmospheres of Venus, Mars and Titan also contain gases that cause greenhouse effects. Greenhouse gases greatly affect the temperature of the Earth; without them, Earth's surface would be on average about $33^{\circ} \mathrm{C}\left(59^{\circ} \mathrm{F}\right)$ colder than at present (Karl and Trenberth, 2003; Le Treut et al., 2007; NASA Report, 2010).

In addition to the main greenhouse gases listed above, other greenhouse gases include sulfur hexafluoride, hydrofluorocarbons and perfluorocarbons. Some greenhouse gases are not often listed. For example, nitrogen trifluoride has a high Global Warming Potential (GWP) but is only present in very small quantities (Le Treut et al., 2007).

Scientists who have elaborated on Arrhenius's theory of global warming are concerned that increasing concentrations of greenhouse gases in the atmosphere are causing an unprecedented rise in global temperatures, with potentially harmful consequences for the environment and human health (Gale, 2005).

The sun is ultimately responsible for virtually all energy that reaches the Earth's surface. Direct overhead sunlight at the top of the atmosphere provides $1366 \mathrm{~W} / \mathrm{m}^{2}$; however, geometric effects and reflective surfaces limit the light which is absorbed at the typical location to an annual average of $\sim 235 \mathrm{~W} / \mathrm{m}^{2}$. If this were the total heat received at the surface, then, neglecting changes in albedo, the Earth's surface would be expected to have an average temperature of $18^{\circ} \mathrm{C}$ (Lashof, 1989). Instead, the Earth's atmosphere recycles heat coming from the surface and delivers an additional $324 \mathrm{~W} / \mathrm{m}^{2}$, which results in an average surface temperature of roughly $+14^{\circ} \mathrm{C}$ (Kiehl et al., 1997).

More than $75 \%$ of heat captured by the atmosphere can be attributed to the action of greenhouse gases that absorb thermal radiation emitted by the Earth's surface. The atmosphere in turn transfers the energy it receives both into space $(38 \%)$ and back to the Earth's surface (62\%), where the amount transferred in each direction depends on the thermal and density structure of the atmosphere.

This process by which energy is recycled in the atmosphere to warm the Earth's surface is known as the greenhouse effect and is an essential piece of Earth's climate. Under stable conditions, the total amount of energy entering the system from solar radiation will exactly balance the amount being radiated into space, thus allowing the Earth maintain a constant average temperature over time. However, recent measurements indicate that the Earth is 
presently absorbing $0.85 \pm 0.15 \mathrm{~W} / \mathrm{m}^{2}$ more than it emits into space (Hansen et al., 2005). This increase, associated with global warming, is believed to have been caused by the recent increase in greenhouse gas concentrations.

The main sources of greenhouse gases due to human activity are: Burning of fossil fuels and deforestation leading to higher carbon dioxide concentrations (Solmon et al., 2007); Livestock enteric fermentation and manure management (Steinfeld et al., 2006), paddy rice farming, land use and wetland changes, pipeline losses, and covered vented landfill emissions leading to higher methane atmospheric concentrations; Use of chlorofluorocarbons (CFCs) in refrigeration systems, and use of CFCs and halons in fire suppression systems and manufacturing processes; Agricultural activities, including the use of fertilizers that lead to higher nitrous oxide $\left(\mathrm{N}_{2} \mathrm{O}\right)$ concentrations.

The seven sources of $\mathrm{CO}_{2}$ from fossil fuel combustion are (with percentage contributions for 2000-2004 (Raupach et al., 2007) :

1. Solid fuels (e.g., coal): $35 \%$

2. Liquid fuels (e.g., gasoline, fuel oil): $36 \%$

3. Gaseous fuels (e.g., natural gas): $20 \%$

4. Flaring gas industrially and at wells: $<1 \%$

5. Cement production: $3 \%$

6. Non-fuel hydrocarbons: $<1 \%$

7. The "international bunkers" of shipping and air transport not included in national inventories: $4 \%$

\subsection{Carbon footprint}

Foot print is a measure of the impact of anthropogenic activities on the environment, in particular climate change. The main source of climate change phenomena is the burning of fossil fuels used for electricity, heating and transportation, which result in emitting the Green House Gases (GHG). Carbon footprint is made up of the sum of our direct emissions of $\mathrm{CO}_{2}$ which comes from the burning of fossil fuels including domestic energy consumption and transportation, and of the indirect $\mathrm{CO}_{2}$ emissions that comes from the whole lifecycle of products we use, starting from the phase of manufacturing till the disposal of these products (IATA, 2008).

The carbon footprint is made up of two parts - primary footprint and the secondary footprint. It can be seen as the total amount of carbon dioxide $\left(\mathrm{CO}_{2}\right)$ and other greenhouse gases emitted over the full life cycle of a product or service. Normally a carbon footprint is usually expressed as a $\mathrm{CO}_{2}$ equivalent (usually in kilogram's or tones), which accounts for the same global warming effects of different greenhouse gases. Carbon footprints can be calculated using a Life Cycle Assessment (LCA) method, or can be restricted to the immediately attributable emissions from energy use of fossil fuels. 
It is well known that carbon dioxide stays in nature for a long time, sometimes up to 100 years, therefore the use of non renewable fuels in transportation has a great significant on the environment. The emissions whether in the air or on the ground have the same impact, but emissions from air transport are continuous, and rapidly growing. Emissions from operations will help identify areas of significant carbon production, allowing for better implementation of reduction strategies and better efficiency results in the end.

The carbon footprint can be efficiently and effectively reduced by applying the following steps: Life Cycle Assessment (LCA) to accurately determine the current carbon footprint; Identification of hot-spots in terms of energy consumption and associated $\mathrm{CO}_{2}$-emissions; Optimization of energy efficiency and, thus, reduction of $\mathrm{CO}_{2}$-emissions and reduction of other GHG emissions contributed from production processes; Identification of solutions to neutralize the $\mathrm{CO}_{2}$ emissions that cannot be eliminated by energy saving measures; The last step includes carbon offsetting, which represents the investment in projects that aim to reducing $\mathrm{CO}_{2}$ emissions, for instance biofuels or tree planting activities.

\subsection{Calculating $\mathrm{CO}_{2}$ Emissions}

Emissions are calculated from a known quantity such as fuel burned, or units of electricity consumed. Combustion of fuel is a stoichiometric chemical reaction, so the mass of $\mathrm{CO}_{2}$ emissions can be directly related to fuel burn (DEFRA, 2008).

Transport represents a different challenge. Fuel consumption can be monitored and converted into a corresponding mass of emissions by multiplying by the appropriate emissions factor (e.g. for petrol $2.317 \mathrm{kgCO}_{2} /$ liter) as reported in DEFRA (2008).

Different greenhouse gas emissions calculators give widely varying results for the same flight due to variations in the underlying assumptions made in the calculator methodology. For example, two different emissions calculators estimate emissions for a return flight from London to New York to be 1.53 (Climate Care, http://www.climatecare.org/) or 3.48 (Atmospheric, http://www.atmosfair.de/index.php?L=3) $\mathrm{tCO}_{2} \mathrm{e}$, a variation of more than a factor of 2. This highlights the huge uncertainty in calculating aviation emissions, and its critical dependence on the methodology adopted. Much of the uncertainty about calculating the environmental impact of aviation emissions derives from the fact that emissions at altitude can instigate a host of chemical reactions in the atmosphere, which each have global warming and cooling effects over a variety of timescales, varying from less than 1 day to several hundred years (Jardine, 2008). The overall effect is certainly one of an increased warming effect compared to emissions at ground level, but the extent of this remains open to debate, both in terms of how to calculate the magnitude of this effect, and what the value should be.

Historically the Intergovernmental Panel on Climate Change (IPCC) quoted a value of 2.7 for this multiplier, with a range of 2-4 (IPCC, 1999). Climate scientists have been able to update this study more accurately and have published a value of 1.9 (http://www.iac.ethz.ch/tradeoff/). More recent studies have questioned the validity of this approach and estimated a value of 1.2 for this effect (Forster et al., 2006, 2007). 
The objectives of this study are:

1- Understand the whole consumption process related to travel and transport in order to find suitable ways to minimize the level of $\mathrm{CO}_{2}$ emitted.

2- Promote the fuel efficiency improvement programs to cut-down the burdens on the environment.

3- Analyze and calculate the effect of air travel operations from cradle to grave, in order to find out the level of pollution they cause during a certain period of time, thus, increasing the awareness of the risks of these operations.

4- Highlight the Royal Jordanian Airlines (RJA) requirements to meets the local and international standards, as well as, regulations of aviation.

\section{Methodology of Calculations}

\subsection{Why Conduct the Analysis of a Carbon Footprint?}

- Powerful tool for analysis

- Quantifies and qualifies emissions

- Identifies sources of emissions

- Tool for decision making

- Provides anchoring for projections

- Tracks impact of changing policy

To Calculate the GHG emissions generated by RJA flights, many steps have been followed in this study, which are:

\subsection{Identify GHG Emissions Sources}

First step was to determine the source of data. It has been done using online information, and previous studies search and investigation to put a plan on how to implement this step in the field.

\subsection{Collecting Data from Royal Jordanian Airlines}

Data collecting were taken from the RJA departments over 2 months period. It was specified and accurate data, and it was taken from actual data of RJA flights records during the year 2009. These data were collected from different related departments such as flight operations at Queen Alia International Airport (QAIA), finance, commercial, airport services, and in-flight services departments, using all available statistics and records.

\subsection{Actual Daily Flight Record (ADFR)}

ADFR system contains the actual information about daily flight record. It was built to record 
all the items in the flight plan that affects the flight time and the duration. Also, it records the movement data for the crew in that flight. Due to the route profitability and performance of crew, the system calculates the fuel consumption and all the fuel data during the flight.

Finally, all the algorithms and calculations for the report contents are prepared strictly to give accurate and valuable information that will be taken as a reference about the fuel consumption for each month. This has been done to have a solid base for the upper management in route profitability, crew performance and aircrafts validity, which will affect decision making process.

\subsection{Using Suitable Systems for Calculations}

Due to the work development to the stage of calculations, a proper and accredited systems, formulas and processes started to be used in this study. After data was collected from the field of action of RJA, using the available measures and systems like Actual Daily Flight Record (ADFR) and department's histories and records, the authors searched many systems and methods to figure out the emission factors that help in calculating the emissions generated from different operations at RJA.

In corporation with Royal Scientific Society (RSS) in Amman, Jordan, steps have taken place to use the Life Cycle Assessment (LCA) software, which helps in finishing all data needed to formulate the calculations used for this study. The calculations were conducted in the Environment and Research Center (ERC) in Royal Scientific Society (RSS) in Amman, Jordan with the aid of specialists in the software used to find out the energy flow of each substance used in the ground and flight operations conduct in Royal Jordanian Airlines. Following is a brief of the LCA software used in the calculation process:

\subsection{Life Cycle Assessment (LCA) Software}

The expression life cycle assessment is a general term for a methodical instrument for applying sound environmental principles to business practices. The essential characteristics of the life cycle assessment method are the calculation of substance and energy flows (inputs and outputs), in principle over their entire lifecycle within a system, and their evaluation against environmental criteria. Life cycle assessment is therefore a quantitative method for the assessment of the environmental impacts of human activities.

The first step involves the calculation of goods, substances and energy flows. The effects on the environment of emissions are then determined on the basis of selected indicators.

An assessment of these environmental impacts can then be made by means of suitable methods. Life cycle assessment is consequently a useful tool for providing information on the impact of products, processes, operations and measures on the environment.

\subsection{Other Steps Used in the Study}

The other steps used to finalize this study were:

1. Collect the activity data and choose the emissions factors used in the study 
2. Select an emissions calculation approach

3. Apply quantification methodology to estimate GHG emissions

4. Find out the total emissions produced by Royal Jordanian Airlines operations during the year 2009 .

\subsection{Company (Royal Jordanian Airlines) Fleet}

RJA environmental mission is to develop and implement strategies and programs for the company that supports its responsibility towards the environment and to improve or maintain environment performance. RJA has developed its own environmental strategy to ensure fully contribution of its share of global carbon dioxide emission reductions by participation and comply with emissions reduction schemes all over the world.

Royal Jordanian Airlines is committed to conducting its operations within the requirements of the laws regarding safety. It ensures that a safe and hazard-free environment for both employees and customers prevails throughout its areas of operation. This can be achieved by meeting or exceeding all flight, the occupational and environmental health and safety standards. RJA put into effect an active mechanism to cut down fuel consumption which in turn will reduce emissions by launching to rationalize fuel consumption during flights.

Royal Jordanian Airlines has its own comprehensive programs for minimizing its impact on the environment which are widely recognized as being among the most responsible and progressive in the industry.

Key elements in selecting new aircraft with their engines and Ground Support Equipment (GSE) are fuel consumption, emissions, and noise levels. The new RJA Boeing 787s on order will reduce emissions by a third, compared to the Airbus A340s and A310s that they will replace.

Environment protection is a key element in the airline's strategy that taken into account in all operations and maintenance processes. RJA has been working hard to reduce all pollutants from aircraft and Ground Support Equipment (GSE) emissions, starting with the gas used in fire extinguishers, aircraft air-conditioning units and waste hazardous materials.

\section{Results and Discussion}

\subsection{Identifying GHG Emissions Sources}

The process of identifying emissions sources from RJA flight operations is typically completed with the following steps:

\subsubsection{Identify Core Direct Emissions Sources}

Emissions generated from flights due to fuel consumption (Jet A-1), form $64 \%$ from the total emissions emitted from any flight operations.

Aircraft engine emissions are composed of approximately $71 \%$ carbon dioxide, $28 \%$ water vapor, and less than one $\%$ each of oxides of nitrogen (NOx), carbon monoxide, oxides of 
sulfur, and other trace components including hydrocarbons such as methane and soot. Aircraft emit significant amounts of carbon dioxide which regards the primary greenhouse gas produced by anthropogenic activities globally. As explained earlier, these emissions contribute in several ways to the global warming.

The calculation of emissions from flight operations is based on the actual transport performance (actual load factor) and the actual quantity of kerosene consumed during the year.

\subsubsection{Calculating Fuel Burn from Flight}

Kerosene (JET A-1) is a type of aviation fuel designed for use in aircraft powered by gas-turbine engines. It has a relatively high flash point of $38^{\circ} \mathrm{C}\left(100^{\circ} \mathrm{F}\right)$, with an auto ignition of $210^{\circ} \mathrm{C}\left(410^{\circ} \mathrm{F}\right)$. This means that the fuel is safe to handle consumption, which is based on actual flight operations, according to the so-called gate to gate principle. This includes all phases of the flight from ground handling services, taxing, to flying detours and holding patterns in the air (Jardine, 2008).

Emissions occur during the Landing and Take Off (LTO) cycle, which includes all activities near the airport that take place below the altitude of 3000 feet $(1000 \mathrm{~m})$. This consists of taxi-out, take-off and climb out, and at the end of the flight, the landing approach and taxi-in. This is the fuel required to get the aircraft into the air (and down again) and are constant irrespective of flight length. Ascents require a much more intense fuel burn than cruising at constant altitude (Caserini et. al., 2007).

The Climb, Cruise and Descent (CCD) cycle is defined as all activities that take place at altitudes above 3000 feet $(1000 \mathrm{~m})$. This fuel use accounts for the bulk of the flight distance, and naturally varies with flight length.

In this work, emissions emitted from RJA flights, will be calculated starting from the LTO and CCD (taxi-off till the landing) as one process due to the lack of specific data for each step.

\subsection{Traffic Growth vs. Fuel Consumption}

Royal Jordanian Airlines has been growing over the years, this growing lead to increase the consumption of fuel, due to the increase of flights and fleet. Combustion emissions from air traffic depend on the type of aircraft, type of engines, fuel used, location (altitude) of operation and traffic volume (number of flights and distance travelled). In this research the International Civil Aviation Organization (ICAO) methodology has been used. This methodology is based on generic emissions calculations. Key features of the ICAO methodology are (Jardine, 2008): 


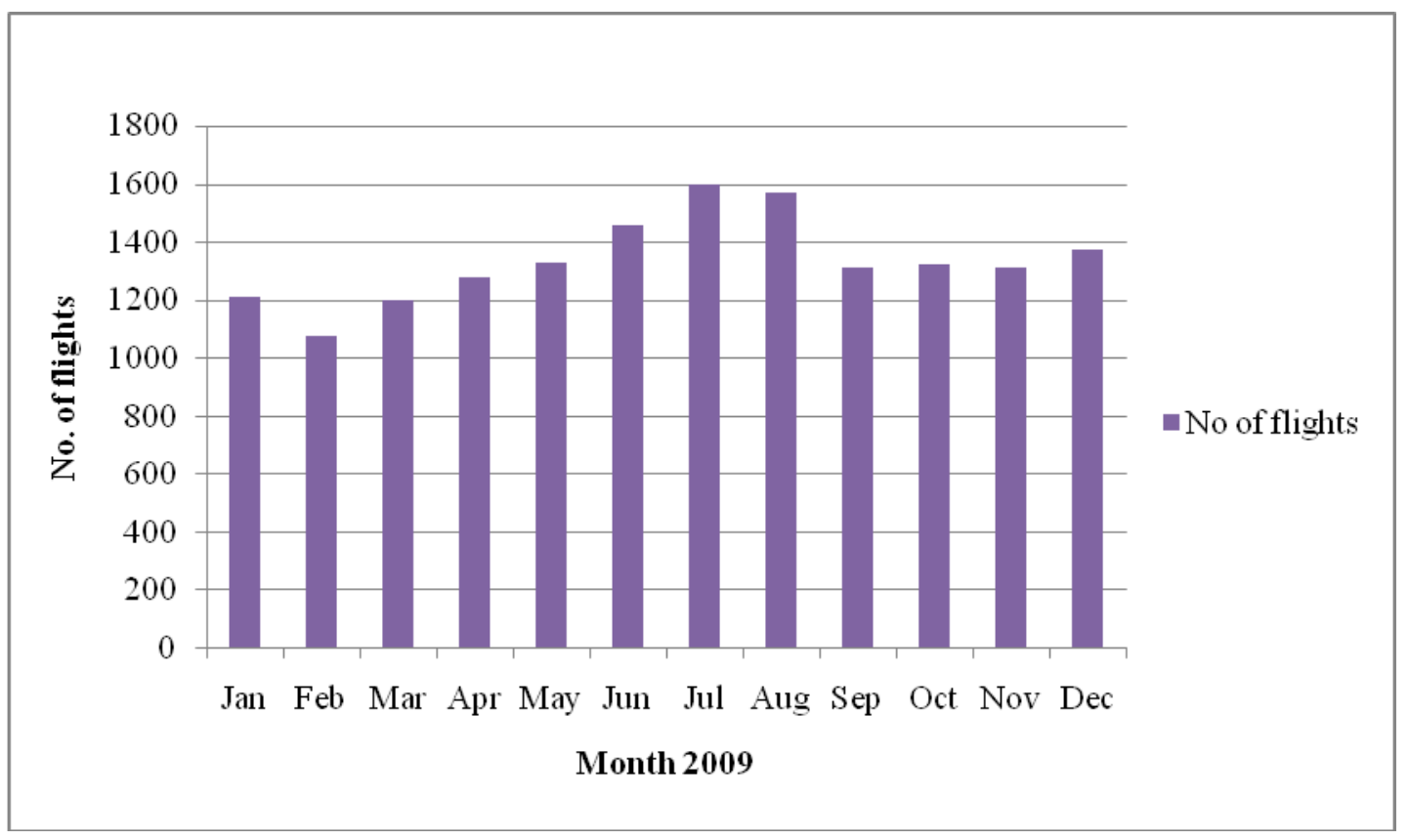

Figure (1): Number of flights took off by RJA air craft during the year 2009.

1. Emissions are calculated as $\mathrm{CO}_{2}$ only and a multiplier is not used. The International Civil Aviation Organization (ICAO) believes that a multiplier should not be used to take account of the non- $\mathrm{CO}_{2}$ effect of aviation until a scientific consensus has been reached on the subject.

$\mathrm{CO}_{2}$ emissions from fuel do not require special calculation methods. They are generated in a fixed relation with the quantity of kerosene consumed during the flight. When fuel oil is burned, it is converted to carbon dioxide and water vapor. Combustion of one kilogram of fuel oil yields 3.157 kilograms of carbon dioxide gas. Carbon dioxide emissions are therefore 3.157 times the mass of fuel burned. This number is used as an emission factor to calculate the emission of $\mathrm{CO}_{2}$ per flight (ton) as shown:

$\mathrm{CO}_{2}$ per flight $($ ton $)=$ Quantity of fuel used $($ ton $) \times 3.157$ (emission factor $)$

Figures that are used and analyzed in this study were for the year 2009. It was drawn on monthly basis. This means that $\mathrm{CO}_{2}$ emissions produced by the flights are calculated over a period of one year. 


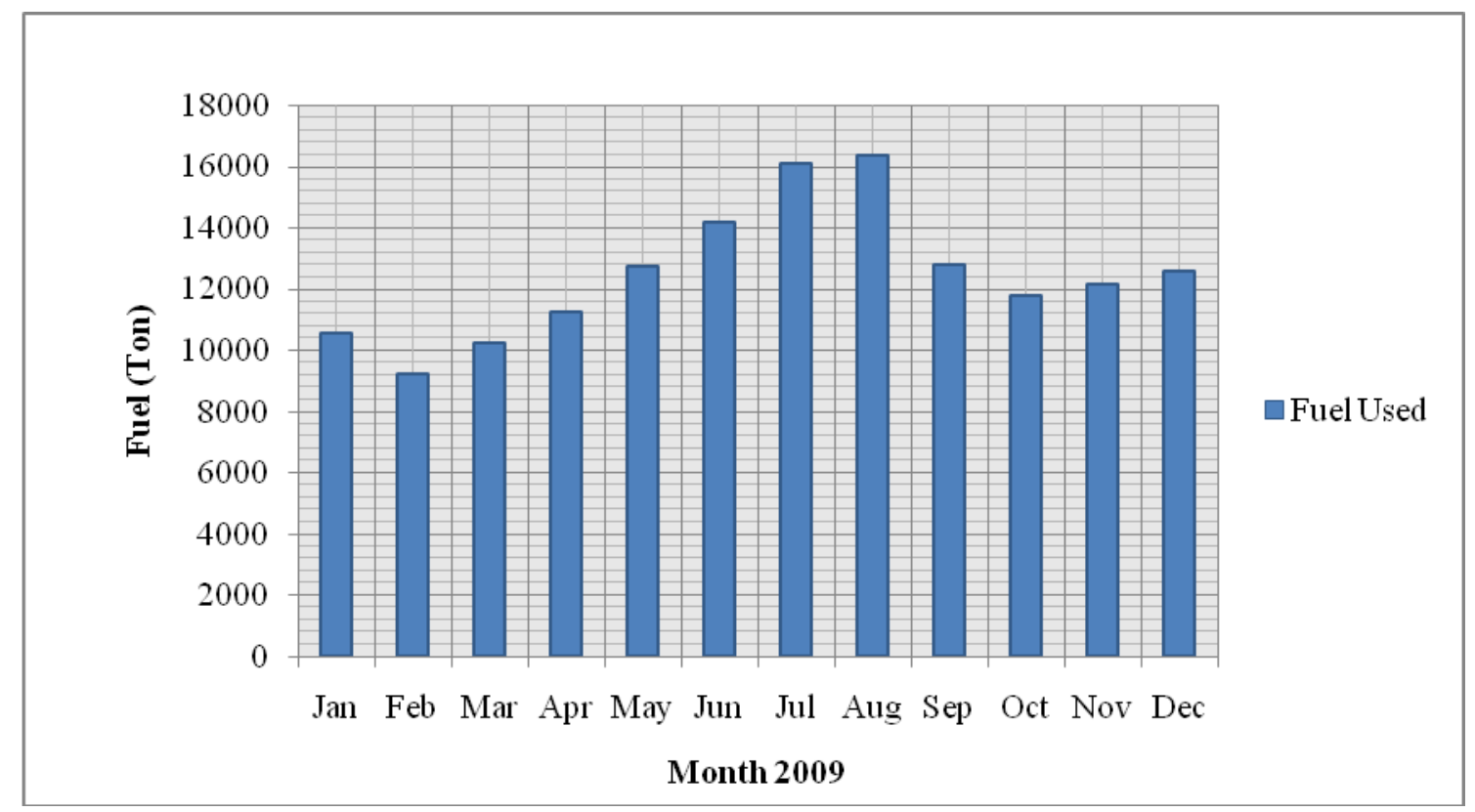

Figure 2: Fuel used by RJA flights during the year 2009.

Figure 2 shows the fluctuation in fuel consumption by flights during the year 2009. The highest fuel quantity used was in August, which is due to the increase of the long-haul flights like North America and Far East in the summer because of holidays shopping festivals, exhibitions, etc. This increase will lead to the increase of fuel quantities that have been used for such flights.

The quantity of fuel used has been tracked and calculated on monthly basis for the whole flights, and based on equation (1) above, the $\mathrm{CO}_{2}$ emissions were calculated and the results were drawn (Figure 3).

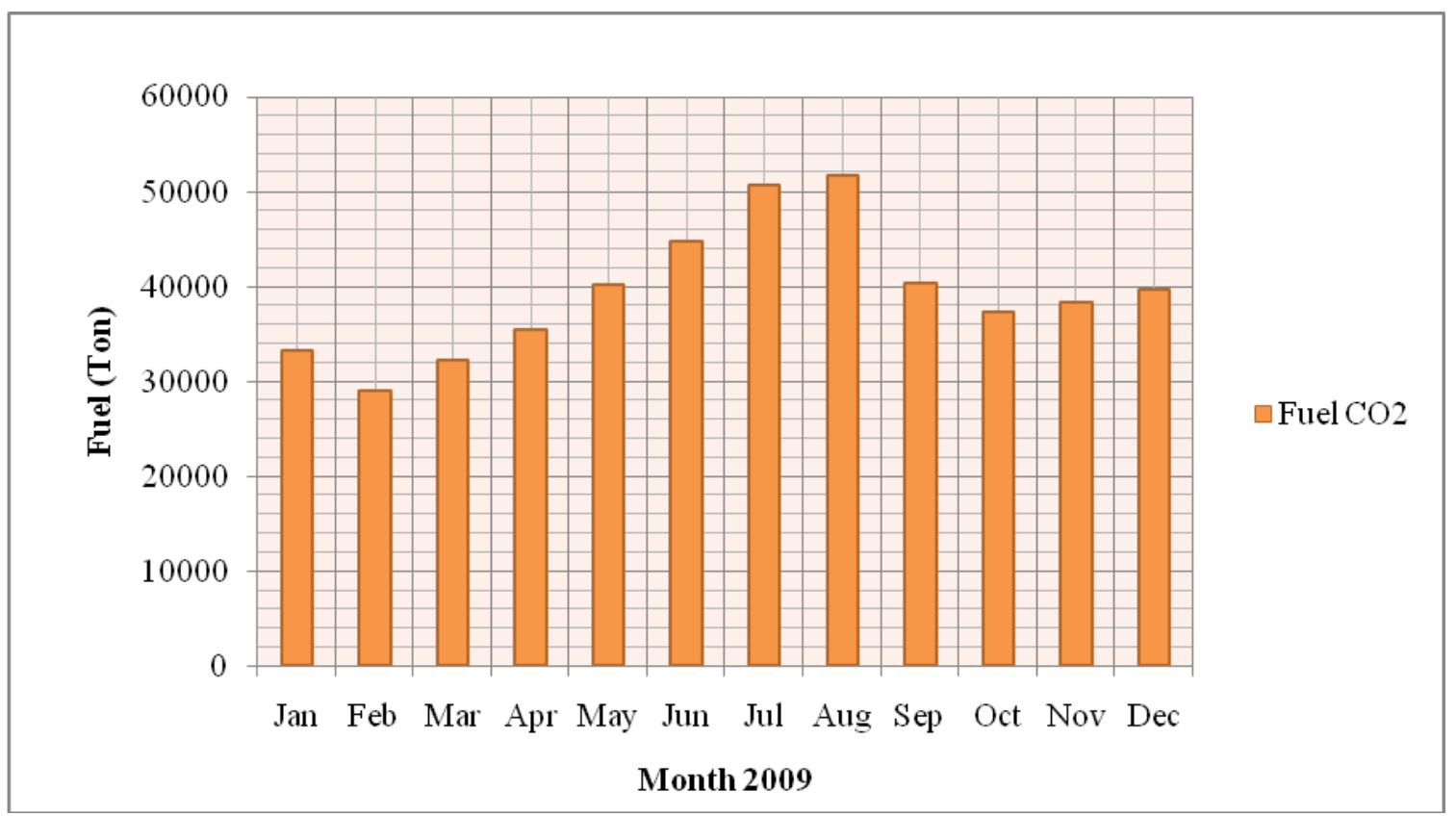

Figure 3: $\mathrm{CO}_{2}$ emissions of the fuel used by RJA flights during the year 2009 . 


\section{Ml Macrothink}

Figure 3 shows that the highest quantity of $\mathrm{CO}_{2}$ emission was in August where the fuel consumption was at its highest level as show in Figure 2. This is due to the direct relation between the fuel quantity and $\mathrm{CO}_{2}$ emission shown in equation 1 .

The relation between fuel quantity and emissions is a direct correlation, so it is clearly that the highest quantity of $\mathrm{CO}_{2}$ emission due to fuel consumption was in August (Figure 3). This is because the Air Cabin (A/C) operates according to the reservation basis and the scheduled flight routes, not on the passenger number. Figure 3 also shows that the calculated total $\mathrm{CO}_{2}$ emitted from Royal Jordanian flights during the year 2009 is 472,880 ton $\mathrm{CO}_{2}$.

2. The ICAO emissions calculator uses aggregated data to estimate the typical emissions associated with a given route between any airport pair, based on $\mathrm{A} / \mathrm{C}$ type.

Table 1 shows the $\mathrm{CO}_{2}$ emission for different types of aircrafts used in RJA during the year 2009.

Table 1: $\mathrm{CO}_{2}$ emissions for different types of RJA aircrafts during the year 2009 .

\begin{tabular}{|llll|}
\hline A/C type & No. of flights & Fuel used (ton) & $\begin{array}{c}\mathbf{C O}_{2} \\
(\text { ton })\end{array}$ \\
\hline A340 & 910 & 12759.3 & 40239.6 \\
\hline A321 & 2090 & 19288.8 & 60885.6 \\
\hline A320 & 2860 & 23808.9 & 71208.8 \\
\hline A319 & 2067 & 9238.27 & 29158.6 \\
\hline A310 & 1094 & 8726.71 & 27537.4 \\
\hline EMJ & 6330 & 72897 & 230123 \\
\hline Total & $\mathbf{1 5 5 1 3}$ & $\mathbf{1 4 6 7 1 8 . 9}$ & $\mathbf{4 5 9 1 5 3}$ \\
\hline
\end{tabular}

Although the flight numbers of A/C Airbus A319 and Airbus A321 are quite similar (Table 1), but the difference in fuel used and $\mathrm{CO}_{2}$ emissions is about a double between these two aircrafts. This is due to the differences in the distance and the flying hours between these two aircrafts, as A321 is used for long distance flight. 


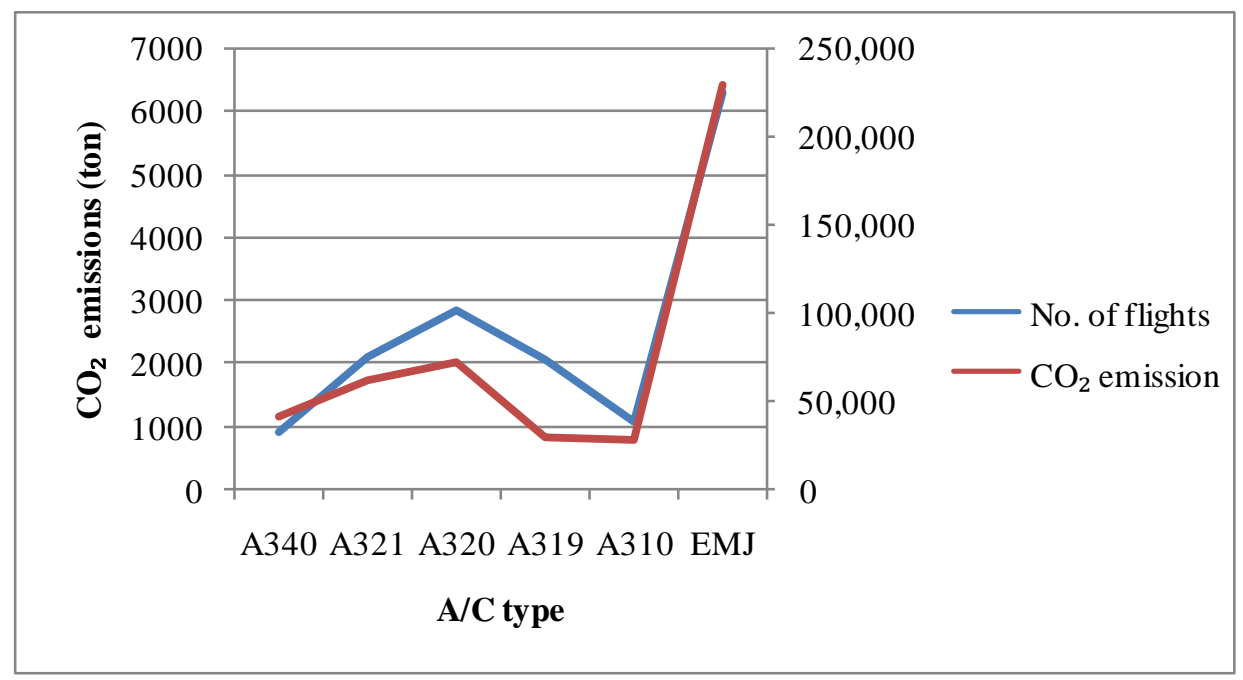

Figure 4: $\mathrm{CO}_{2}$ emissions per air craft vs. flight no. during the year 2009.

The highest record of flights shown in Figure 4 is for the Embarear (EMJ) type aircrafts. This is because those types of planes operate for short destinations, so that they run more flights than any other kinds of aircrafts.

3. Seating configurations are calculated from the number of economy seats that can be fitted inside the aircraft based on a standard cabin layout. Crown class has been ignored in this study because of the lack of data that separate the crown class from the economy class, which means that according to the system used in this study, all data were taken based on total number of seats and not its type.

4. Emissions are allocated per passenger, based on a passenger load factor. This factor also varies by route or distance, and by seat configuration on a specific $\mathrm{A} / \mathrm{C}$ type.

\subsection{Passenger Footprint}

To calculate the emissions per passenger for a certain flight, lots of data need to be collected and calculated based on RJA records and statistics. Calculating specific consumption and emission, requires absolute values in relationship to transport performance. That is to say, the ratio ton per passenger (ton/pax) is calculated on the basis of:

\subsubsection{Actual Load Factors (Passenger Number, Passenger Weight, Cargo, Mail)}

Number of passengers during 2009 was changed due to different in seasons and period of the year is shown in Figure 5). 


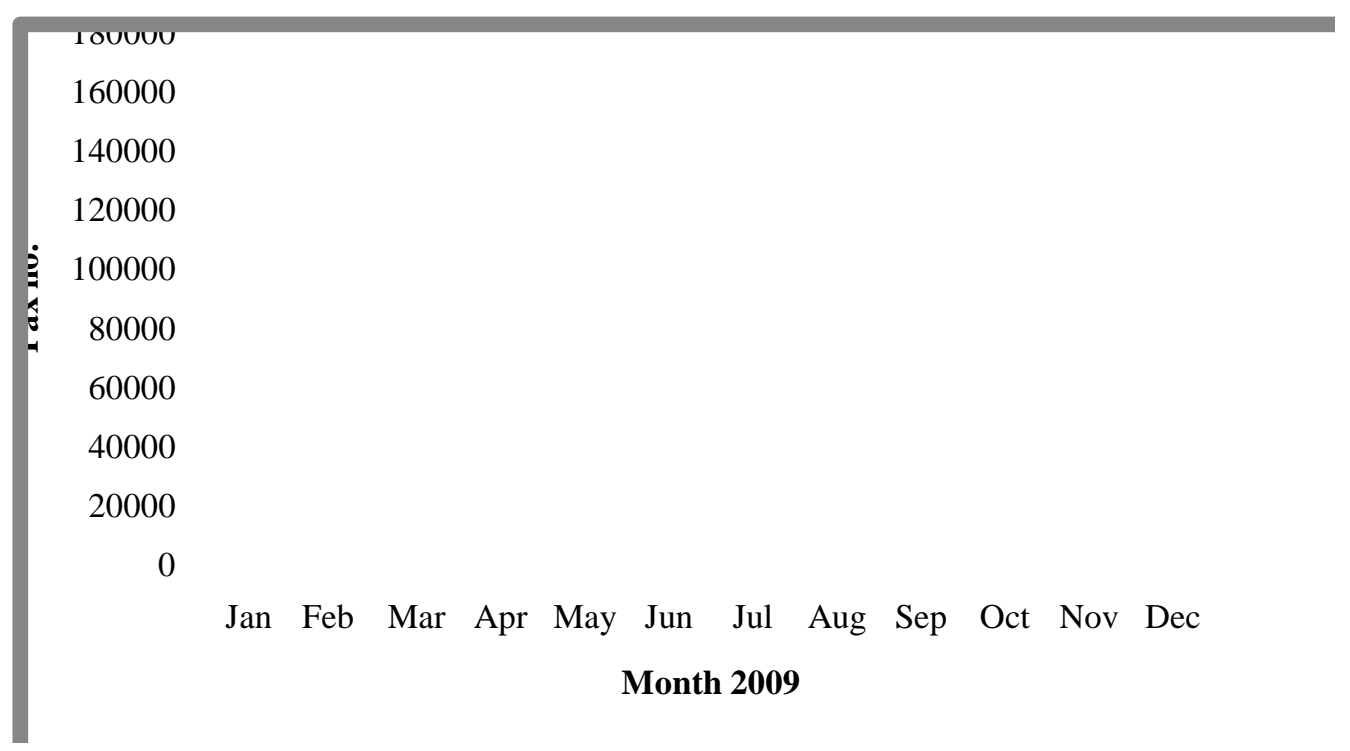

Figure 5: Monthly number of passengers in RJA flights for the year 2009.

\subsubsection{Choosing Airports (Distance Flown)}

The first method used is the airport locations. It is more accurate method because the emissions are calculated based upon the actual distance flown. The total distance is calculated using the 2 specified airport locations (based on the 'Great Circle' method of calculating distances, where the distance is the shortest between any two points on the surface of a sphere).

Flight distance is an essential factor in determining fuel consumption. Generally speaking, the farther the route, the more fuel burned. However, since takeoff and landing demand higher fuel burn rates than level flight, shorter routes where takeoff and landing comprise a larger portion of the overall flight tend to be less efficient (i.e. require more fuel per $\mathrm{km}$ ). This drops away such that flights over $2000 \mathrm{~km}$ in A3190, E195 and E175. Takeoff and landing are smaller portions of the overall flight for medium range routes, so they are generally more efficient. In addition, over very long distances the fuel use per $\mathrm{km}$ increases because of the greater amount of fuel that has to be carried during the early stages of flight.

The destination that RJA flies to, have been divided into regions based on IATA names which are the flight routes to Arabian Gulf, Levant, North Africa, Europe, Fareast (Asia) and North America and Canada.

\subsection{Estimation of Ground Support Equipment Contribution}

Aircraft are not the only source of aviation emissions. Airport access and ground support vehicles produce similar emissions. Such vehicles include traffic to and from the airport, ground equipment that services aircraft, and shuttle buses and vans serving passengers.

Ground support equipment in total is usually the second largest contributor to local air pollution at an airport. It includes emissions from the non moving aircraft (e.g. Auxiliary Power Units, APU), all Ground Support Equipment (including Ground Power Unit GPU) for 


\section{Macrothink}

handling aircraft, and all vehicles circulating on airside premises (e.g. sweeper trucks, crew busses, catering trucks, cargo tractors, etc).

Ground support equipments are also considered basing on fleet data and fuel consumption in every airport, as well as average emission factors proposed for fuel type. The simplest way to predict the $\mathrm{CO}_{2}$ emissions emitted by GSEs is to multiply (the emission factor of the fuel type used) by (the quantity used by the equipment in a certain period of time). Usage of equips refers to the hours of use for a specific equipment type either to service one Landing and Takeoff Cycle (LTO) of a specific aircraft type or for the entire inventory period

GSE emissions of significance are hydrocarbon (HC), carbon monoxide (CO), oxides of nitrogen (NOx), particulates $(\mathrm{PM})$, and sulfur dioxide $\left(\mathrm{SO}_{2}\right)$. For conventional and alternative fuel GSE, the factors that determine the quantity of pollutant emitted are the emission factor, average rated brake horsepower of an equipment type's engine, load factor (the average operational horsepower output of the engine divided by its rated BHP), and usage (GSE age).

\subsubsection{GSE Emissions - Calculation Methodology}

The following equation calculates the pollutant emissions from an individual unit of equipment:

$\operatorname{Eit}(K g)=(B H P \times$ LFt $x$ Ut $\times$ Elit $)$

where:

Eit - emissions per year of pollutant $i$ produced by GSE type $t(\mathrm{Kg})$

$B H P t$ - average rated brake horsepower (BHP) of the engine for equipment type $t$

$L F t$ - load factor utilized in ground support operations for equipment type $t$

$U t$ - annual hours of use for equipment type $t$

EIit - emission index (or emission factor) for pollutant $i$, in grams per BHP-hr, which is specific to a given for diesel engines and fuel type

$i$ - Pollutant type $\left(\mathrm{CO}_{2}\right)$

$t$ - Equipment type (e.g., diesel baggage tug)

In general, the data gathered has covered most of the GSE types identified above. The remaining gaps are mainly in the lower priority categories. For these gaps, no data were directly obtained from sources, nor were sufficiently unambiguous data available for estimates to be made (Arbor, 1995).

Total $\mathrm{CO}_{2}$ emissions emitted from fuel consumption by GSE which served 15513 RJA flights at QAIA during 2009 are 372,312 Ton $\mathrm{CO}_{2}$.

Use of electric GSE or Aerospace Ground Equipment (AGE) produces no emissions at the airport or air base but generating the electricity needed to operate them. Electricity used at an airport to recharge an electric vehicle like Auxiliary Power Units (APU) providing electricity 
and air conditioning to aircraft parked at airport terminal gates.

Emission inventory electricity, emission factors are based on average emissions intensity of total electric sector generation for specified countries or country-based regions and include Transmission and Distribution (T\&D) losses incurred in delivering electricity to the point of use

Since emissions associated with electric GSE come from the local electricity rather than at the point where the equipment is used, the electric GSE emissions are not calculated, and thus it is considered as indirect emissions.

\subsection{Identify Core Indirect Emissions Sources}

Every business has some processes, products, or services that generate direct and/or indirect emissions from one or more broad source categories. Almost all businesses generate indirect emissions due to the purchase of electricity for use in their processes or services such as catering and products provide on board.

\subsubsection{In-flight Products}

In-flight products rely on purchased materials to conduct services. Most of these materials will not emit GHG when used, but emissions most likely occur during the procurement of raw materials and the manufacture and disposal process.

Most of the emissions calculations for each source are based on estimating or obtaining fuel use (or activity) information and then multiplying by the appropriate $\mathrm{CO}_{2}$ emission factor.

The emission factors calculated in this study are derived from LCA program which concerned with the accounting of materials and energy flow involved in the life cycle of a product or service and the assessment of associated environmental impact based on Intergovernmental Panel on Climate Change (IPCC) formulas and inventories. The emissions generated from these materials, are either during usage, storage or disposal of these materials. It is calculated based on the weight of each substance or good and the quantity which consumed during the desired period of time, taking into consideration the emission factor as shown below:

$\mathrm{CO}_{2}$ emission $(\mathrm{Kg})=$

Weight of the product (Kg) x Quality consumed (piece) $x$ Emission factor

The total $\mathrm{CO}_{2}$ emissions emitted from these services during 2009, which were used to serve 15513 flights, are 4,027.4 Ton.

\subsubsection{Catering}

Part of emissions produced from RJA operations is from the meals and beverages served on the $\mathrm{A} / \mathrm{C}$ during the flight. The distance and time of the flight is the main reason to determine the number and kind of meals and services dish up on board. Logically, a long-haul flight needs more equipments, tools and meals. This increases the weight of the $\mathrm{A} / \mathrm{C}$ as well as increase the fuel consumption of the flight. 


\section{Macrothink}

The emissions produced from these meals and equipments are part of the total fuel consumed for a certain flight and related to pax (passengers) number on board.

\subsection{Identify Optional Emissions Sources}

\subsubsection{Chemicals and Detergents}

Solvents and related compounds are important for Greenhouse Gas (GHG) and other emission inventories because they are a significant source of emissions of Non-Methane Volatile Organic Compounds (NMVOCs). No other GHGs are emitted in significant amounts from the use of solvents and related compounds, which include chemical cleaning substances used in dry cleaning, printing, metal degreasing, and a variety of industrial applications as well as household use.

Emissions are produced through evaporation of the volatile chemicals when these products are exposed to air.

In this study, LCA is the main source for the emission factors data. The system does not deal with the chemicals and detergents as separate components. The emission factor for all cleaners and detergents is 1.52 , depending on the price and sales of the solvent as mentioned above.

RJA uses the cleaners and the solvent to make sure that the cabin and all part inside the $\mathrm{A} / \mathrm{C}$ is clean and up to client satisfaction, as well as, to meet the international aviation standard. Many liquids and substances are used to achieve this purpose.

$\mathrm{CO}_{2}$ emissions created from the use of these chemicals and cleaners are calculated based on the quantity consumed for the duration of one year or per month as shown in the table below. 


\section{Macrothink}

Journal of Public Administration and Governance ISSN 2161-7104 2012, Vol. 2, No. 4

Table 2: Quantities of chemicals used by Cabin Appearance (C/A) during 2009 and tons of $\mathrm{CO}_{2}$ emissions produced.

\begin{tabular}{|c|c|c|c|}
\hline Month & No. of flight served & Consumption (liter) & $\mathrm{CO}_{2}$ (ton) \\
\hline Jan & 1113 & $1,767,396$ & 10,548 \\
\hline Feb & 1025 & $1,627,656$ & 09,748 \\
\hline Mar & 1062 & $1,686,410$ & 10,099 \\
\hline Apr & 1229 & $1,951,599$ & 11,688 \\
\hline May & 1233 & $1,957,951$ & 11,726 \\
\hline Jun & 1317 & $2,091,339$ & 12,524 \\
\hline Jul & 1407 & $2,234,255$ & 13,380 \\
\hline Aug & 1485 & $2,358,116$ & 14,122 \\
\hline Sep & 1368 & $2,172,325$ & 13,009 \\
\hline Oct & 1156 & $1,835,678$ & 10,993 \\
\hline Nov & 1254 & $1,991,298$ & 11,925 \\
\hline Dec & 1477 & $2,345,412$ & 14,046 \\
\hline Total & 15126 & $24,019,438$ & 143,808 \\
\hline
\end{tabular}

As explained before, emissions produced from these materials calculated as follow:

$\mathrm{CO}_{2}$ emission $(\mathrm{Kg})=$

Weight of the consumed material $x$ Total price $x$ Emission factor of $\mathrm{CO}_{2}$ per $\$$

Total $\mathrm{CO}_{2}$ emissions emitted from the chemicals and detergents use for cabin appearance during 2009, serving 15513 flights, are 143,808 Ton. 


\subsection{Royal Jordanian Airlines Total Emission During 2009}

Table 3: Total emission from air and ground operations of RJA fleet at, QAIA.

\begin{tabular}{|l|l|l|l|l|l|l|}
\hline Month & $\begin{array}{l}\text { No. of } \\
\text { flights }\end{array}$ & Fuel used & $\begin{array}{l}\text { Fuel used by } \\
\text { GSE }\end{array}$ & $\begin{array}{l}\text { Chemicals } \\
\text { detergents } \\
\text { used }\end{array}$ & $\begin{array}{l}\text { In-flight } \\
\text { products } \\
\text { used }\end{array}$ & Total \\
\hline Jan & 696 & $33,207.4$ & $16,704.0$ & 10,548 & 181.0 & $\mathbf{6 0 , 6 4 0 . 4}$ \\
\hline Feb & 1076 & $29,085.5$ & $25,824.0$ & 9,748 & 279.8 & $\mathbf{6 4 , 9 3 7 . 3}$ \\
\hline Mar & 1197 & $32,237.3$ & $28,728.0$ & 10,099 & 311.2 & $\mathbf{7 1 , 3 7 5 . 5}$ \\
\hline Apr & 1275 & $35,462.6$ & $30,600.0$ & 11,688 & 331.5 & $\mathbf{7 8 , 0 8 2 . 1}$ \\
\hline May & 1330 & $40,228.3$ & $31,920.0$ & 11,726 & 345.8 & $\mathbf{8 4 , 2 2 0 . 1}$ \\
\hline Jun & 1455 & $44,687.8$ & $34,920.0$ & 12,524 & 378.3 & $\mathbf{9 2 , 5 1 0 . 1}$ \\
\hline Jul & 1597 & $50,704.0$ & $38,328.0$ & 13,380 & 415.2 & $\mathbf{1 0 2 , 8 2 7 . 2}$ \\
\hline Aug & 1572 & $51,687.5$ & $37,728.0$ & 14,122 & 408.7 & $\mathbf{1 0 3 , 9 4 6 . 2}$ \\
\hline Sep & 1313 & $40,328.3$ & $31,512.0$ & 13,009 & 341.4 & $\mathbf{8 5 , 1 9 0 . 7}$ \\
\hline Oct & 1320 & $37,259.2$ & $31,680.0$ & 10,993 & 343.2 & $\mathbf{8 0 , 2 7 5 . 4}$ \\
\hline Nov & 1311 & $38,301.4$ & $31,464.0$ & 11,925 & 340.9 & $\mathbf{8 2 , 0 3 1 . 3}$ \\
\hline Dec & 1371 & $39,690.8$ & $32,904.0$ & 14,046 & 356.5 & $\mathbf{8 6 , 9 9 7 . 3}$ \\
\hline Total & 15513 & $\mathbf{4 7 2 , 8 8 0 . 1}$ & $372,312.0$ & $\mathbf{1 4 3 , 8 0 8 . 0}$ & $\mathbf{4 , 0 3 3 . 4}$ & $\mathbf{9 9 3 , 0 3 3 . 5}$ \\
\hline
\end{tabular}

As can be noticed from Table 3, the total $\mathrm{CO}_{2}$ emission for Royal Jordanian Airlines during the year 2009 was $993,033.5$ ton. This number of $\mathrm{CO}_{2}$ emission $(993,033.5)$ needs to be minimized. This can be done by having lots of corporations and initiative efforts to reduce it, and to achieve greener operations and business.

\section{Conclusions}

In recent years, substantial improvements have been made regarding aircraft emissions. For example, aircraft engines now are less pollutant and more fuel efficient, and reduction of 
airframe weight has resulted in even better fuel efficiency. This is in addition to the recent modifications in the new airplane wings which in turns lead to reduce of fuel consumption. The amount of fuel burnt is directly linked to the emission of $\mathrm{CO}_{2}$. The RJA step in ordering new generation aircrafts of most efficient in fuel consumption, will by default reduce quantities of fuel consumed per aircraft and in turn reduce $\mathrm{CO}_{2}$ emission.

Royal Jordanian Airlines has to reduce its carbon-footprint, by using this assessment to look outside of the entity. This step must be taken by RJA to increase the efficiency of operations and looking seriously in using renewable energy sources to reduce carbon-footprint of its operations and products use.

The main issue that, most of the $\mathrm{CO}_{2}$ or GHG emitted by travel operations cannot, be avoided or hard to manage, like; fuel used in the aircraft. Using alternative fuel will cost the company a lot of money that cannot handle or the turn over payback needs long period of time to be sensed.

The statistics and calculations of the emissions emitted from RJA operations in this research shows that the highest percentage of pollution is due to fuel consumption from aircrafts is 47.6\%, and the rest was 37.5 for the fuel consumption of GSEs and 14.9\% from other operations like catering, flight products and chemicals. Mean while the international studies as mentioned in section 3.1.1 confirm that the highest emissions in the air operations emitted from fuel consumption from aircrafts is $64 \%$ and $36 \%$ from the rest. This concludes that there is a mismanagement of products and chemicals usage and consumption. Lack of awareness of the important and hazards of using excess quantities by the labors and employees leads to misuse of these materials and this in turn produce much more emissions and waste.

Royal Jordanian Airlines is doing its best to minimize the fuel consumption from its flights by reducing the weight for every flight can be loaded, to minimize quantity of fuel used by this flight. This is will reflected on the $\mathrm{CO}_{2}$ emissions emitted from the flight. On the other hand, there are several areas where improvement seems to be possible. One such area is in the raw materials, in which RJA can reduce its footprint in the instance in these areas. This can be done by switching to recycled and more environmental friendly materials.

\section{Acknowledgments}

The authors thank the Environment Research Center (ERC) located at the Royal Scientific Society in Amman, Jordan for their valuable assistance in using the software needed to complete the LCA calculations.

\section{References}

Arbor A., (1995), Technical Data to Support FAA'S Advisory Circular on Reducing Emissions from Commercials Aviation. U.S. Department of Transportation Aviation Administration, Washington, DC, Prepared by: Energy and Environmental Analysis Inc. 1655 North Fort Myer Drive, Suite 600 Arlington, Virginia 22209, September 29, 1995.

Caserini S., Monguzzi A. M., Fraccaroli A., Moretti M., and Angelino E., (2007), Emission inventory of airport activities in Lombardy (Italy): methodologies and results. Lombardy 
Regional Environmental Protection Agency - Viale Restelli 3/1 20124 Milan, Italy, s.caserini@arpalombardia.it.

Forster P. M., Shine K. P., Stuber N., (2006), It is premature to include non - $\mathrm{CO}_{2}$ effects of aviation in emissions trading schemes, Atmospheric Environment, 40 (6), 1117-1121.

Forster P. M., Shine K. P., Stuber N., (2007), Corrigendum to "It is premature to include non- $\mathrm{CO}_{2}$ effects of aviation in emission trading schemes Atmospheric Environment, 41(18), 3941.

DEFRA (Department of environment, food, and rural affairs), (2008), Act on $\mathrm{CO}_{2}$ Calculator: Data, Methodology and Assumptions, Paper V1.2 August 2008".

Gale T., (2005), Global Warming and Alternative Energy Sources Research, Opposing Viewpoints Resource Center, Detroit, On line at: http://www.allfreeessays.com/topics/opposing-viewpoints-resource-center/0.

Hansen J., Nazarenko L., Ruedy R., Sato Mki., Willis J., Del Genio A., Koch D., Lacis A., Lo K., Menon S., Novakov T., Perlwitz Ju., Russell G., Schmidt G.A., and Tausnev N, (2005), Earth's energy imbalance: Confirmation and implications, Science, 308, 1431-1435,

IATA (International Air Transport Association), (2008), Aviation and Climate Change, Presentation to GIACC - ICAO, Montreal. February 26, 2008, On line at: http://www.icao.int/env/meetings/Giacc/Iata.pdf.

IPCC (Intergovernmental Panel on Climate Change), (1999), Intergovernmental Panel on Climate Change, "Aviation and the global atmosphere", IPCC, Geneva, 1999.

Jardine C.N., (2008), "Calculating the Environmental Impact of Aviation Emissions - 2nd Edition”, ECI, University of Oxford.

Karl, T. R., Trenberth K. E., (2003), Modern global climate change. Journal of American Science, 302(5651): 719-23.

Kiehl J. T. and Trenberth K. E., (1997), Earth's annual global mean energy budget. Bulletin of the American Meteorological Association, 78: 197-208.

Lashof D. A., (1989), The dynamic greenhouse: Feedback processes that may influence future concentrations of atmospheric trace gases and climatic change. Climatic Change, 14 (3): 213-242.

Le Treut H., Somerville R., Cubasch U., Ding Y., Mauritzen C., Mokssit A., Peterson T. and Prather M., (2007)., Historical Overview of Climate Change Science in: Climate Change 2007: The Physical Science Basis. Contribution of Working Group I to the Fourth Assessment Report of the Intergovernmental Panel on Climate Change (Solomon, S, Qin, D, Manning, M, Chen, Z, Marquis, M, Averyt, KB, Tignor, M and Miller, HL, editors), Cambridge University Press, On line at: http://ipcc-wg1.ucar.edu/wg1/Report/AR4WG1_Print_Ch01.pdf. 


\section{Macrothink}

NASA (National Aeronautics and Space Administration), (2010), Science Mission Directorate article on the water cycle, On line at: http://science.nasa.gov/earth-science/oceanography/ocean-earthsystem/ocean-water-cycle/.

Raupach M. R., Gregg M., Philippe C., Corinne L., Josep G. Canadell, Gernot K., and Christopher B. F., (2007), Global and regional drivers of accelerating $\mathrm{CO}_{2}$ emissions. Proceeding of National Academic Science, U.S.A. 104 (24): 10288-93.

Solomon S., Qin D., Manning M., Chen Z., Marquis M., Averyt K. B., Tignor M., and Miller (eds.) H. S., (2007), "Chapter 7. Couplings Between Changes in the Climate System and Biogeochemistry". Climate Change 2007: The Physical Science Basis. Contribution of Working Group I to the Fourth Assessment Report of the Intergovernmental Panel on Climate Change. Cambridge, United Kingdom and New York, NY, USA: Cambridge University Press. ISBN 978-0-521-88009-1.

Steinfeld H., Gerber P., Wassenaar T., Castel V., Rosales M., de Haan C., (2006), Environmental issues and options. FAO Livestock, Environment and Development (LEAD) Initiative. ISBN: 978-92-5-105571-7, FAO/LEAD, Rome (Italy). 